\title{
La imprenta en la escuela: pedagogía del sujeto único y el trabajo cooperativo
}

No se hace beber al caballo que no tiene sed. Célestin Freinet

Resumen

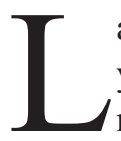
a nueva geografía humana en su carácter global y multidimensional instaura un mundo hiperconectado de acelerada innovación tecnológica. La educación superior enfrenta el desafío de operar en torno y dentro de emergencias culturales disímiles emanadas de tales dinámicas. La propuesta es resituar lo humano como eje vital, en contraparte del economicismo que afecta al medio ambiente, a la identidad cultural, al tejido social y al ámbito político. Es una proposición compleja y al mismo tiempo permisible, ya que desde el aula se gestan las transformaciones en el ser, conocer y hacer de los alumnos. En función de lo anterior, se intenta reinstalar, a través de la pedagogía de Célestin Freinet, aquella relación primigenia entre maestro-alumno, misma que, a manera de extrapolación, fue realizada en el contexto universitario como una experiencia de aprendizaje significativo que implicó tres momentos sustanciales: potenciar las facultades de la persona, reinventar el concepto incluyente y expansivo de la imprenta como dispositivo análogo al internet y, las nuevas tecnologías destinadas a dinamizar el trabajo individual y colectivo del alumno en la vida real.

Palabras clave: pedagogía Freinet, sujeto único, imprenta en la escuela, trabajo colaborativo.

\section{Introducción}

La educación es el bien de la humanidad reconocido abiertamente como sustancial para desarrollar al individuo en sociedad; sin embargo, algo está pasando: a mayor tecnología, producción de conocimiento o información, el mun- do está más convulso y la persona más cooptada por lo material. A fines del siglo pasado, Manuel Castells (1997) inducía la manera de enfrentar estas condiciones: "Hay que contar con una brújula y con un ancla, la brújula: educación, información, conocimiento, tanto a nivel individual como colectivo. El ancla, nuestras identidades, saber quiénes somos y de dónde venimos para no perdernos a donde vamos" (p. 5). Por otra parte, McLuhan (1996) reconoce consecuencias mentales y sociales "porque el «mensaje» de cualquier medio o tecnología es el cambio de escala, ritmo o patrones que introduce en los asuntos humanos" (p. 30); y en otro sentido, Horkheimer y Adorno (1944) afirman que "el individuo se ve reducido a cero frente a las potencias económicas" (p. 4).

Estas cuestiones están latentes en los estudiantes universitarios, por ello, el interés de influir performativamente en su proyecto de vida. Acorde a las consideraciones anteriores, desde 1977, ${ }^{1}$ el Movimiento Cooperativo de la Escuela Popular de Cantabria [MCEPC] promueve "Una Pedagogía para el siglo xxı" (2009), bajo el siguiente argumento: "[...] entendemos que a pesar de que ha pasado mucho tiempo desde que Freinet empezara su andadura como maestro, a pesar de que sus escritos han quedado un poco 'viejos' desde el punto de vista del lenguaje intelectual de moda, no es menos cierto que los problemas que existían existen y que la cruda realidad es, con otros colores, con otras formas, la misma" (pp. 3-4). Coincidentemente, el MCEPC visiona la problemática global, al mismo tiempo que sustenta y gestiona por igual las tres órdenes fundamentales de la pedagogía Freinet: tres principios que conciernen a las finalidades de la es-

1 El Movimiento Cooperativo de la Escuela Popular nace desde 1930 y alcanza su consolidación en Granada, España, en 1977, diez años después de fallecido Freinet. 

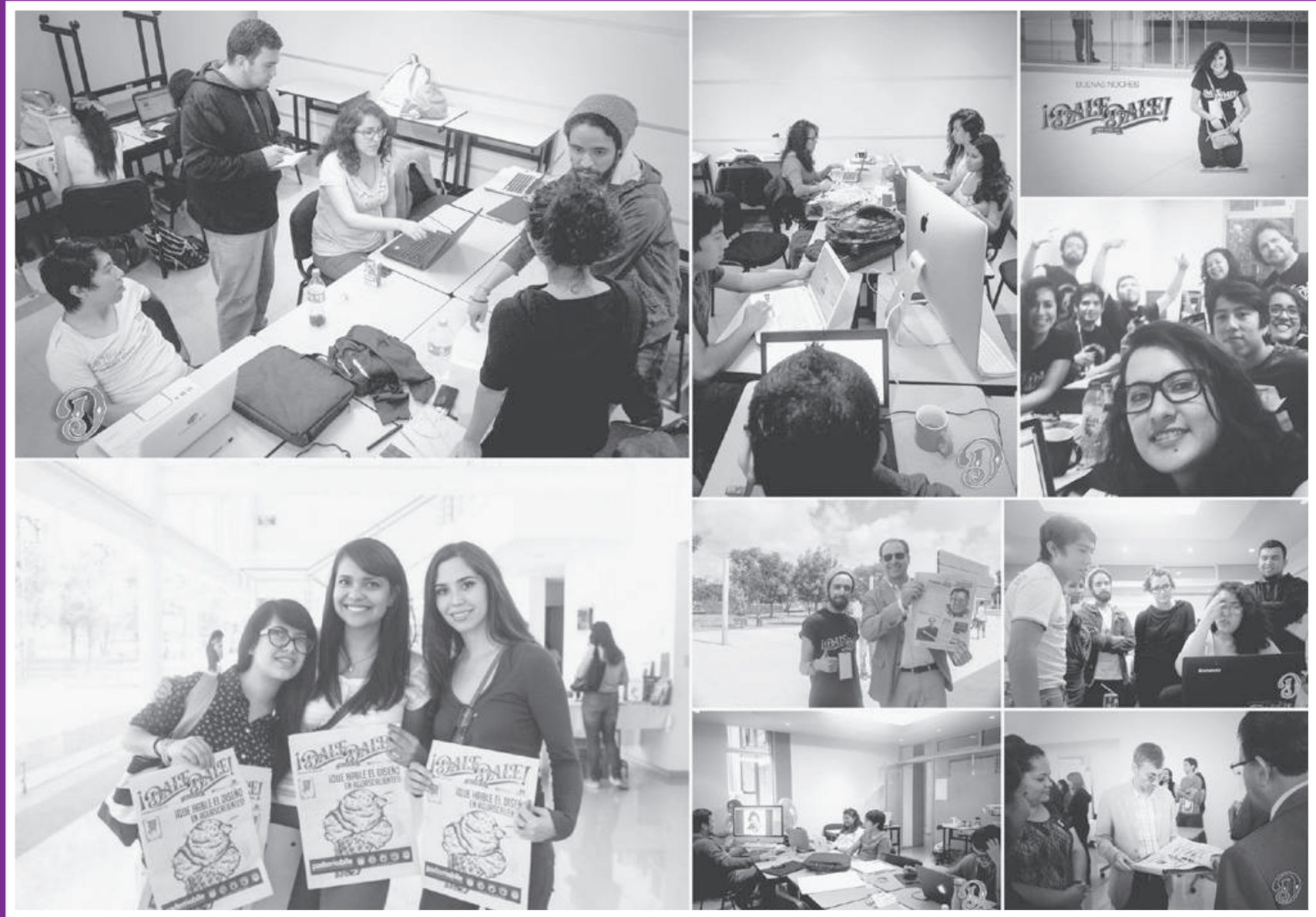

Figura 1. Collage sobre el desarrollo de la edición del periódico Dale Dale, en el año 2014, uAA (fotografía de Homero Posada).

cuela; tres principios fundamentales que conciernen a los aprendizajes; las técnicas y un espíritu: dispositivos instituyentes de interacción y socialización. Este corpus fue la pauta para realizar la experiencia de aprendizaje cooperativo bajo el concepto de "la imprenta en la escuela", materializado a través del periódico Dale Dale de la Licenciatura en Diseño Gráfico de la Universidad Autónoma de Aguascalientes.

Un día del maestro, en fecha lejana que la memoria no atrapó, se transmitía por televisión un viejo filme que refería las vivencias laborales de un maestro rural. El protagonista emulaba la figura de Célestin Freinet en la escuela de Saint Paul, de los Alpes Marítimos franceses. Dicho personaje bregaba por hacer de escuela y contexto una forma libre de enseñar y aprender a través de la vida, en contra y parte de los postulados de la educación en Francia: "escolástica o de los caminos seculares", "que escritores, sabios, administradores eminentes han dicho ser los caminos a la verdad: ¡No a la debilidad afectiva! ¡Mantened la ley! ¡Acostumbrad a vuestros alumnos a obedecer, incluso sobre todo si la orden dada contraría sus tendencias y deseos!" (Freinet, 1995: 11). Con esta vehemencia, el mentor cuestionaba el estatus educativo de aquella época. Las escenas y la trama quedaron en memoria de aquel filme, titulado $L^{\prime e ́ c o l e ~ b u i s s o n n i e ̀ r e ~}{ }^{2}$, donde se reviven los momentos más significativos y álgidos que vivió el desarrollo de la pedagogía Freinet.

¿Por qué tan alta estima obra una pieza cinematográfica? El valor está en dos razones humanas: la primera, el paralelismo biográfico con quien suscribe el presente: origen humilde, internado en la educación secundaria, maestro rural a la misma edad, con intervención social en la comunidad y apasionado de las técnicas tipográficas; y la segunda, la vocación docente, los postulados pedagógicos que motivaron nuevas estrate-

2 Filme dirigido por Jean-Paul Le Chanois en 1949. En el año 2017 surge la versión L'école buissonnière, dirigida por Nicolás Vanier, que retoma algunos conceptos de la pedagogía Freinet. Su enfoque es llevado a la educación de la vida y su mímesis con la naturaleza. 
gias para "dar sed"3 a sus alumnos de la escuela de Saint Paul. El filme fue suficiente para motivar el estudio de la obra de Freinet y llevar a la práctica sus premisas con los alumnos, a través del periódico universitario Dale Dale, durante los eventos de "Interdiseño 2013"4 y "Hablo Diseño 2014", 5 del Centro de Ciencias del Diseño y de la Construcción de la UAA.

La estructura del proyecto fluye entre las tres órdenes fundamentales arriba mencionadas:

1. Tres principios que conciernen a las finalidades de la escuela:

- La escuela abierta a la vida. "[...] indica voluntad de apertura al ambiente natural y social inmediato, y también voluntad de apropiación activa de una cultura escolar [...]" (Peyronie, 2001: 122). Al presentar la propuesta del periódico a los alumnos que cursaban la asignatura de "Diseño Gráfico Publicitario I", la apropiación activa fue inmediata, enfrentaron con voluntad, compromiso y apertura los imponderables sucintos en el proceso de creación y las contingencias naturales de la producción.

- La educación del trabajo. Freinet retoma el concepto de juego-trabajo: "cree en el interés de la participación de los niños en un trabajo verdadero y productivo, fuera de toda explotación y enajenación" (Peyronie, 2001: 123). Dale Dale se produjo como una práctica profesional libre, viva y real, los estudiantes gestionaron la información gráfica y textual, redactaron las notas, diseñaron la estructura editorial en forma y contenido, negociaron patrocinios y maquilas de impresión, hasta llegar a la distribución de los ejemplares.

- La escuela popular. Este principio se funda en la Escuela Moderna francesa, constituida "por maestros

3 Parábola que enfatiza el carácter motivador de la enseñanza, separado de contenidos ortodoxos y más congruente a las actividades propias de la naturaleza del niño (Freinet, 1995: 20-22).

4 Reconocimiento, edición 2013: Olympia Cirenia García, Eder Fabián del Valle, Juan Pablo Lozano, Juan Osvaldo López, Gerardo Dávila, Sandra Arrieta, Paola Jeaneth Escobar, Tanya Ivette Navarro, Sonia Estefanía Camarena, Stefanie Montserrat Vázquez, José Luis Rivera, Alicia Stephanie Barrales, Byron Cervantes y Octavio Daniel Valadez.

5 Reconocimiento, edición 2014: Paulina Calvillo Cantú, Janis Estefanía Jiménez, Alejandro Padilla, Christian Jaime Flores, Mario Alberto Solís, José Luis Hernández, Andrea Miroslava Rodríguez, Andrea Macías, Christian Alejandro Castañeda, Alma Lorena Cecilio y Ricardo Sahel Pacheco. movilizados, que están comprometidos de manera voluntaria con el éxito de los logros de la mayor cantidad de niños" (Peyronie, 2001: 123). La UAA, en su carácter público y autónomo, semeja aquella escuela popular sin distingo de clases. La totalidad del grupo construyó vivencialmente sus aprendizajes con determinación y esfuerzo compartido.

2. Tres principios fundamentales que conciernen a los aprendizajes:

- El tanteo experimental. "En los tanteos el individuo mide y ejerce no solamente sus propias posibilidades, sino que también intenta tomar del medio ambiente recursos susceptibles de reforzar su potencial de poder. El ambiente es más o menos complaciente, más o menos dócil, más o menos útil. Tan pronto es recurso, y tan pronto es barrera, a menudo es una mezcla de ambos" (Freinet en Peyronie, 2001: 131). En Dale Dale se vivieron estos contrastes, su capacidad de asumir riesgos propició éxitos y frustraciones frente al entorno académico, la burocracia institucional y el terreno social.

- La libre expresión. Este principio encauza al niño "para que exprese el yo social y el yo afectivo, el dispositivo de escuchar proporcionando las técnicas del texto libre (de su lectura a otros, de su puesta a punto, de su difusión)" (Peyronie, 2001: 133). Es este punto, el alumno se convierte en eje central, donde gravitan maestro y actores educativos; es entidad angular indivisible, único, auténtico, singular, sensible y dúctil; es "la valoración del niño no como ente abstracto [...] sino como un sujeto único al que la pedagogía tiene obligación de ayudar en su proceso de formación" (Freinet, 1995: 1). Dale Dale se creó como un diálogo de jóvenes para jóvenes. Se respetó la libre expresión, la autonomía de pensamiento y creación. La difusión consumó afectos y satisfacciones personales y colectivas.

- El método natural. "Es la expresión y comunicación por intermediación de signos escritos, aun si su mecánica está imperfectamente ajustada. Lo esencial es a través de los signos, entender o adivinar la idea de las indicaciones que expresan [...]. Lo esencial es subirse a la bicicleta" (Peyronie, 2001: 111). La prensa digital e impresa es un producto visual por excelencia, 
no es dominio total de los diseñadores, es resultado de un trabajo multidisciplinario. Al respecto, en Dale Dale se reconocieron significados y operaciones que distaban del dominio total de la encomienda, incluso en el campo del diseño. A pesar de ello, la inclusión en la práctica profesional fue aprendizaje natural, llegó a la meta en bicicleta.

3. Las técnicas y un espíritu: dispositivos instituyentes de interacción y socialización:

- Representan el aporte distintivo de Freinet, definido como "materialismo pedagógico" "porque toda técnica supone un material" (Peyronie, 2001: 16). Estos dispositivos permiten la existencia de los principios en el aula y son determinados por Freinet como dispositivos instituyentes: "la práctica cooperativa para la organización del trabajo y para la regulación de las relaciones interpersonales; la personalización de los aprendizajes; la creatividad, la expresión libre; la apertura a la alteridad en el orden de las culturas antropológicas" ${ }^{\prime 6}$ (Peyronie, 2001: 134). Freinet integra a su clase cerca de 30 prácticas, dispositivos, técnicas o herramientas, de las cuales destacan: la cooperativa escolar, los intercambios interescolares, la biblioteca del trabajo [вT] y principalmente la imprenta en la escuela. Sobre este último dispositivo, se promueve en la Universidad el periódico Dale Dale, con los principios que le dan significación humana individual y colectiva al sentido de aprendizajes que proveen distintamente la escuela, el trabajo y la vida.

Desde 1925, se implementó el manejo técnico del

«Es necesario replantear una pedagogía

que revierta los efectos de pedagogías

"acuarteladas" y permita experiencias docentes

creativas, versátiles, que faculten profesionales

eficaces y efectivos, realizados y solventes para organizarse entre sí.»
6 Este dispositivo instituyente es el resultado de las publicaciones realizadas con la imprenta escolar, en particular, se creó el denominado Libro de la vida, compartido desde 1925 con otras escuelas y culturas que incorporaron la imprenta (Peyronie, 2001: 134). sistema de impresión a través de tipos móviles; es decir, la tradicional prensa de Gutenberg, y no fue únicamente el aprendizaje técnico de la imprenta, sino el concepto de aprendizaje asociativo, cooperativo, centro de conocimientos de comunicación interescolar y aporte psicológico y pedagógico. En Dale Dale se realizaron dos ediciones: la primera, con mil ejemplares diarios durante tres días, y la segunda, con cuatro mil por día en cuatro días. El concepto de "imprenta en la universidad" representó el aprendizaje de los jóvenes en su ámbito natural con el uso potencial de las TIC - tan revolucionarias como lo fueron en su momento-, la invención de la escritura y la imprenta.

En las Figuras 2 y 3 se observan contrastes tecnológicos, culturales, sociales y educativos, donde los principios pedagógicos de Freinet se muestran inalterables. Una escena de la película sobre Freinet destaca por la expresión de júbilo grupal entre los niños cuando se imprime la primera página en la imprenta. El acto se repite por igual en los universitarios, al momento en que su periódico brota entre los rodillos de impresión de la imponente rotativa ${ }^{7}$ para hacerse vivo y palpable. A la vista saltan por miles las imágenes y textos elaborados con creatividad, trabajo, talento y pasión. Y al otro día se hace la luz, igual que brota la idea de la imprenta en Freinet; Dale Dale emerge materializado con el trabajo individual y colectivo de un pequeño grupo de estudiantes que distribuyen públicamente sus ideas y pensamientos, quienes gritan orgullosamente la superación de sus metas al convertirse literalmente en "voceros" de sus aprendizajes.

\section{Conclusión}

La pedagogía del sujeto único implica, por sí misma, parte y consecuencia del trabajo colectivo, porque el intercambio de significados simbólicos propicia en el individuo influencias para su construcción personal y visión futura. El trabajo cooperativo que Freinet desarrolló responde a las necesidades actuales en que la dialéctica del individuo-colectividad debe ser dialógica y dinámica. Es necesario replantear una pedagogía que revierta los efectos de pedagogías "acuarteladas" y permita experiencias docentes creativas, versátiles, que faculten profesionales eficaces y efectivos, realizados y solventes para organizarse entre sí. La demanda es el cambio de actitudes y aptitudes con fluidez, flexibilidad, conocimiento e ima-

7 Impresión en rotativa. Periódico Dale Dale. Basado en la Pedagogía Freinet. Disponible en: https://youtu.be/ONaZ8mNOFHo. 


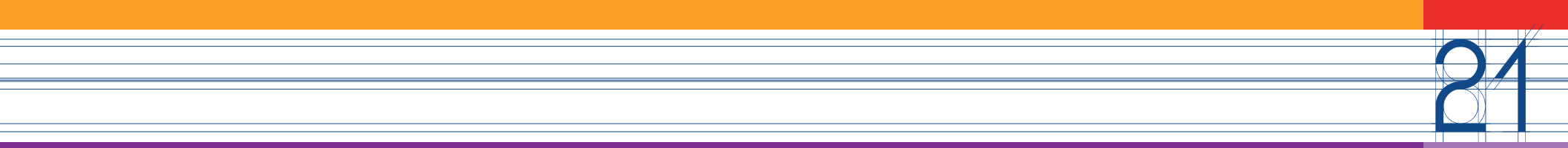

Héctor Homero Posada Ávila DOCERE

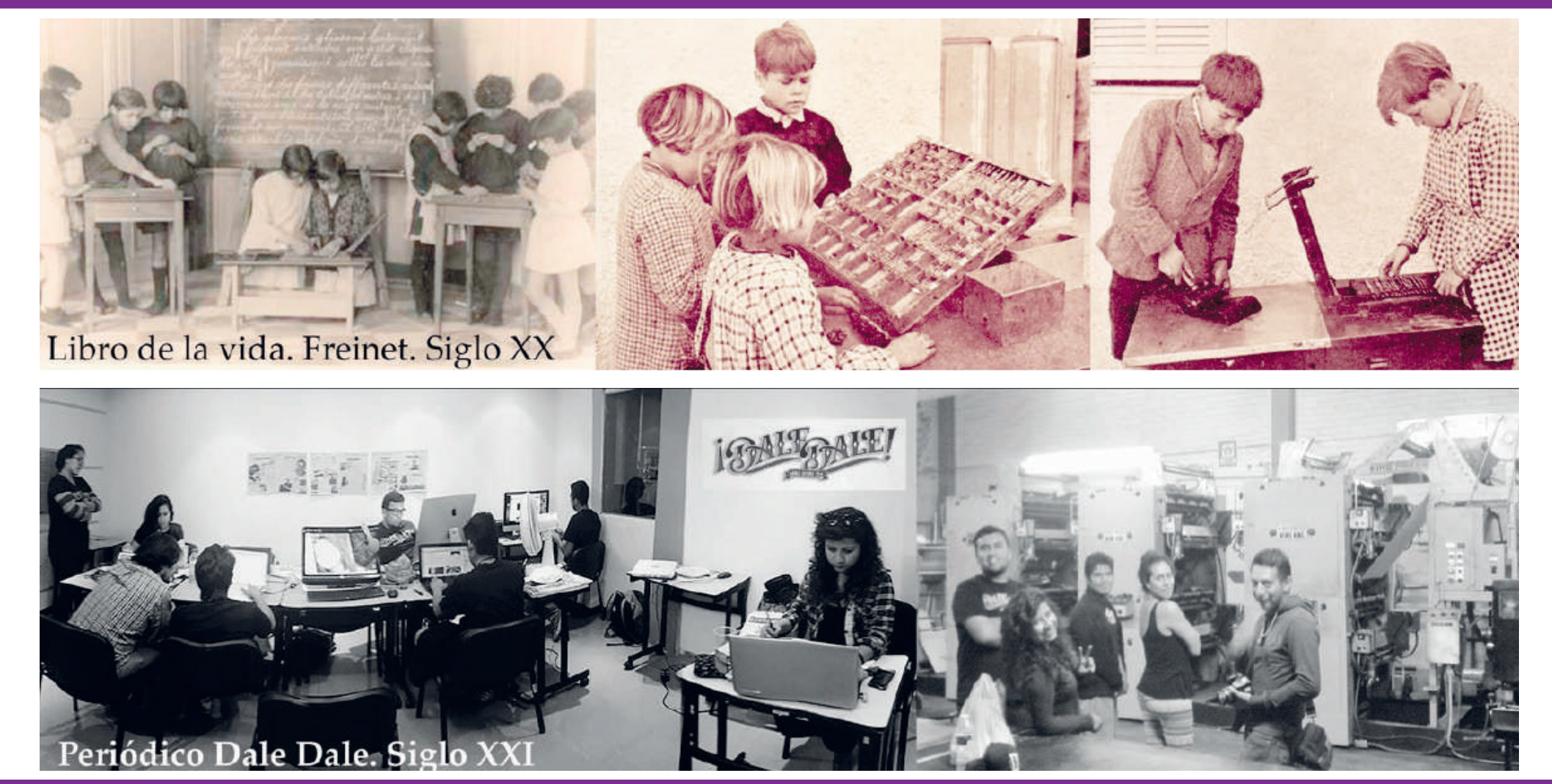

Figura 2 (superior). Libro de la vida. La imprenta en la escuela de Freinet, en la escuela de Vence, Alpes Marítimos franceses, año de 1940 (collage, Homero Posada. Fotografías anónimas). Figura 3 (inferior). Dale Dale. Proceso de diseño, edición e impresión del periódico en el año 2014, UAA (collage y fotografía, Homero Posada).

ginación, donde la multiplicidad de información pueda tener sentido y dirección en el sujeto, capaz de inspirar sed a los demás. Suficiente será transformar la clase, alejarnos de la cotidianidad que ciega, o bien, retomar la historia y regresarle la luz opacada por la luminosidad artificiosa del presente.

Fuentes de consulta

Castells, M. (1997). La era de la información: economía, sociedad y cultura. La Sociedad Red. Volumen I. Madrid: Alianza Editorial, S. A.

Corti (Prod.) y Chanois, J. (Dir.). (1949). L'école buissonnière. [Cinta cinematográfica]. Francia: Union Generale Cinematographique.

Freinet, C. (1995). Parábolas para una Pedagogía Popular. España: Planeta-Agostini.
Horkheimer, M. y Adorno, T. (1944). Dialéctica del iluminismo. Recuperado de: https://bit.ly/2GoNLYn. MCEP de Cantabria (2009). Frainet. Una pedagogía para el siglo XXI. Santader: Universidad de Cantabria. Recuperado de: https://es.calameo.com/ books/001885745f4cef4d0fe30.

MCEP de Madrid (1983). El Movimiento Cooperativo de la Escuela Popular. Vida Escolar, (2), 113-122.

McLuhan, M. (1996). Comprender los medios de comunicación. Las extensiones del ser humano. España: Ediciones Paidós Ibérica, S. A.

Peyronie, H. (2001). Pedagogía y emancipación. México: Siglo XXI Editores.

Posada, H. H. (2014). Collage y fotografía. Creación del periódico Dale Dale. [Figura 2].

$\mathrm{s} / \mathrm{a}(\mathrm{s} / \mathrm{f})$. Libro de la vida. La imprenta en la escuela de Freinet, en la escuela de Vence, Alpes Marítimos franceses, año de 1940. [Figura 1]. Recuperado de: https://bit.ly/2J64u4q. 